\title{
Association of body mass index and waist circumference with high blood pressure in older adults
}

\author{
Wenli Zhang ${ }^{1}$, Kun He${ }^{1}$, Hao Zhao ${ }^{1}$, Xueqi Hu' ${ }^{1}$ Chunyu Yin², Xiaoyan Zhao² and Songhe Shi ${ }^{\text {* }}$
}

\begin{abstract}
Background: The relationship between obesity and prevalent high blood pressure in older adults has predominantly been estimated using categorical measures of body mass index (BMI) and waist circumference (WC), masking the shape of the dose-response relationship. We aimed to examine the precise relationship of BMI, WC with high blood pressure and to assess the appropriate level of BMI and WC for high blood pressure.

Methods: We examined data for 126,123 individuals in Xinzheng city aged $\geq 60$ years from a population based study from January to December 2019. Logistic regression and restricted cubic spline models were applied to assess the relationship and the appropriate level of BMI and WC for high blood pressure. An additive interaction analysis was used to test synergistic effects between a higher BMI and WC for high blood pressure.

Results: The full-adjusted odds ratios (ORs) with 95\% confidence intervals (Cls) of an increase of $1 \mathrm{~kg} / \mathrm{m}^{2}$ in BMl and $1 \mathrm{~cm}$ in WC for high blood pressure were 1.084 (1.080-1.087) and 1.026(1.024-1.027), respectively. Multivariable adjusted restricted cubic spline analyses showed the nonlinear relationships of BMI and WC with high blood pressure in both men and women (all $P<0.001$ ). The risk of high blood pressure increased steeply with increasing BMl from $\geq 25 \mathrm{~kg} / \mathrm{m}^{2}$ and $W C \geq 88 \mathrm{~cm}$ or $86 \mathrm{~cm}$ for males and females, respectively. And we observed a significant additive interaction between a higher BMI and WC such that the prevalence of high blood pressure was significantly enhanced.

Conclusion: These findings suggest increased high blood pressure prevalence in the older adults with increased $\mathrm{BMl}$ and $\mathrm{WC}$. BMI $\leq 25 \mathrm{~kg} / \mathrm{m} 2$ and $\mathrm{WC} \leq 88 \mathrm{~cm}$ or $86 \mathrm{~cm}$ for males and females may be the best suggestion with regard to primary prevention of high blood pressure in older adults.
\end{abstract}

Keywords: High blood pressure, Body mass index, Waist circumference, Restricted cubic spline, Additive interaction

\section{Background}

Hypertension is a substantial public health burden [1] and a strong modifiable risk factor for cardiovascular disease [2], which has become one of the leading causes of global mortality, accounting for 9.4 million deaths each year [3, 4]. From 2010 to 2017, the weighted

\footnotetext{
* Correspondence: zzumrssh@gs.zzu.edu.cn

'Department of Epidemiology and Health Statistics, College of Public Health, Zhengzhou University, Songhe Shi, 100 Kexue Avenue, Zhengzhou, Henan 450001, People's Republic of China

Full list of author information is available at the end of the article
}

prevalence of hypertension increased by $23.4 \%$ and is increasing with aging in China [4]. Obesity is one of the modifiable risk factors associated with cardiovascular disease [5-7], which is most generally assessed by body mass index (BMI) and waist circumference (WC). Commonly, BMI is used as a substitute for general obesity because of its strong correlation with gold standard body fat [8-10], and WC is regarded as a better index for evaluating abdominal obesity [11].

C C The Author(s). 2021 Open Access This article is licensed under a Creative Commons Attribution 4.0 International License, which permits use, sharing, adaptation, distribution and reproduction in any medium or format, as long as you give appropriate credit to the original author(s) and the source, provide a link to the Creative Commons licence, and indicate if changes were made. The images or other third party material in this article are included in the article's Creative Commons licence, unless indicated otherwise in a credit line to the material. If material is not included in the article's Creative Commons licence and your intended use is not permitted by statutory regulation or exceeds the permitted use, you will need to obtain permission directly from the copyright holder. To view a copy of this licence, visit http://creativecommons.org/licenses/by/4.0/. The Creative Commons Public Domain Dedication waiver (http://creativecommons.org/publicdomain/zero/1.0/) applies to the data made available in this article, unless otherwise stated in a credit line to the data. 
Accumulating evidence suggests a potential link between obesity-related high blood pressure (HBP) [12$14]$, but controversy exists about the degree of the associations between two anthropometric indicators and the risk of HBP. And information about the relationship between BMI, WC and HBP is limited in older adults. In particular, few studies have explored the dose-response relationship and investigated the interaction between $\mathrm{BMI}$ and WC. In addition, higher BMI and WC increase the risk of HBP alone, but their interrelations with an increased risk of HBP remain uncertain.

Thus, in this study, we aimed to assess the independent association of BMI and WC with $\mathrm{HBP}$ as well as their possible additive interactions on the risk of HBP using a large and contemporary population in central China and to explore the appropriate level of BMI and WC for the older adults.

\section{Methods}

\section{Study population}

The study population consisted of participants of a comprehensive health check-up program conducted at fourteen medical examination centers (Supplementary 1). Generally, the Central People's Government of China demands that residents aged $\geq 60$ years participate in health examinations annually to promote good health by enabling early detection of chronic diseases and associated risk factors. The study collected clinical, demographic, and lifestyle information from all participants by face-to-face interviews, physical examinations and blood biochemical examinations. Cross-sectional study data from Xinzheng from January to December 2019 were combined for analyses. For this study, 1969 people were excluded from the current study due to missing physical examination data $(n=117)$ or biochemical test data $(n=1852)$. Finally, we had data for 58,115 men and 68,008 women resident $\geq 60$ years of age, who were enrolled to assess the association between BMI, WC and HBP (Fig. 1). Written informed consent was obtained from each participant before data collection. The research ethics committee of Zheng Zhou University approved the current study methodology, protocol, and procedures. (Reference Number: ZZUIRB2019-019).

\section{Exposure}

Height, weight, and WC were measured twice by trained nurses following rigorous protocols. Body height was measured without shoes with a stadiometer, and body weight was measured with participants in light clothing and without shoes by electronic scales. WC was measured with gentle breathing at the midpoint between the lowest rib and the iliac crest to the nearest $0.1 \mathrm{~cm}$. BMI was calculated as weight $(\mathrm{kg})$ divided by the square of height (m). BMI was categorized into quintiles (Male: <
22.20, $22.20 \sim 24.02,24.02 \sim 25.73,25.73 \sim 27.78, \geq 27.78$ Female: <22.43, $22.43 \sim 24.42, \quad 24.4 \sim 26.27, \quad 26.27 \sim$ $28.58, \geq 28.58$ ). And WC was categorized into quintiles (Male: $<81,81 \sim 86,86 \sim 90,90 \sim 96, \geq 96$ Female: $<79,79 \sim$ $84,84 \sim 89,89 \sim 95, \geq 95)$.

\section{Outcome}

Systolic blood pressure (SBP) and diastolic blood pressure (DBP) were collected according to the World Health Organization definition [15]. After sitting quietly for five minutes, certified nurses measured each participant's seated blood pressure three times using a mercury sphygmomanometer (Omron HEM-7125, Kyoto, Japan). We calculated the means of SBP and DBP. Diagnosis of HBP was defined as $\mathrm{SBP} \geq 140 \mathrm{mmHg} /$ or DBP $\geq 90$ $\mathrm{mmHg}$ or use of antihypertensive medication within 2 weeks [15].

\section{Covariates}

Information on demographic characteristics (age, sex, marital status, and place of residence) and behavioral measures (smoking, physical exercise and alcohol consumption) were obtained by a standardized questionnaire, which was in strict accordance with the National Standards for Basic Public Health Services (2011). Marital status was categorized as unmarried, married, divorced and death of a spouse. Smoking status was defined as current smoker, former smokers, or never smoker [16]; Alcohol consumption and physical exercise status were categorized as never, once in a while, more than once a week and every day. Place of residence (rural and urban) was defined according to countryspecific definitions. Stroke was defined as sudden onset of a focal, non-convulsive neurological deficit persisting longer than $24 \mathrm{~h}$. Diagnosis of psychotic illnesses was met Diagnostic and Statistical Manual of Mental Disorders (DSM - 5) criteria for a diagnosis within the spectrum of primary psychotic illnesses. Diagnosis of cancer based on the International Classification of Diseases. Overnight fasting blood samples were collected into vacuum tubes for assessing serum levels of blood glucose using standard methods.

\section{Statistical analysis}

Continuous data were expressed as the mean \pm standard deviation (SD) and categorical data as the number (percentage) for quintiles of BMI or WC, using different values for men and women. Comparisons of the basic characteristics of the quintiles were performed with the $X^{2}$ test, ANOVA, and Kruskal-Wallis test.

Logistic regression models were used to estimate the adjusted odds ratios (ORs) with 95\% confidence intervals (CIs) for BMI, WC and HBP, taking the quintile with the lowest baseline BMI or WC values as the reference. 


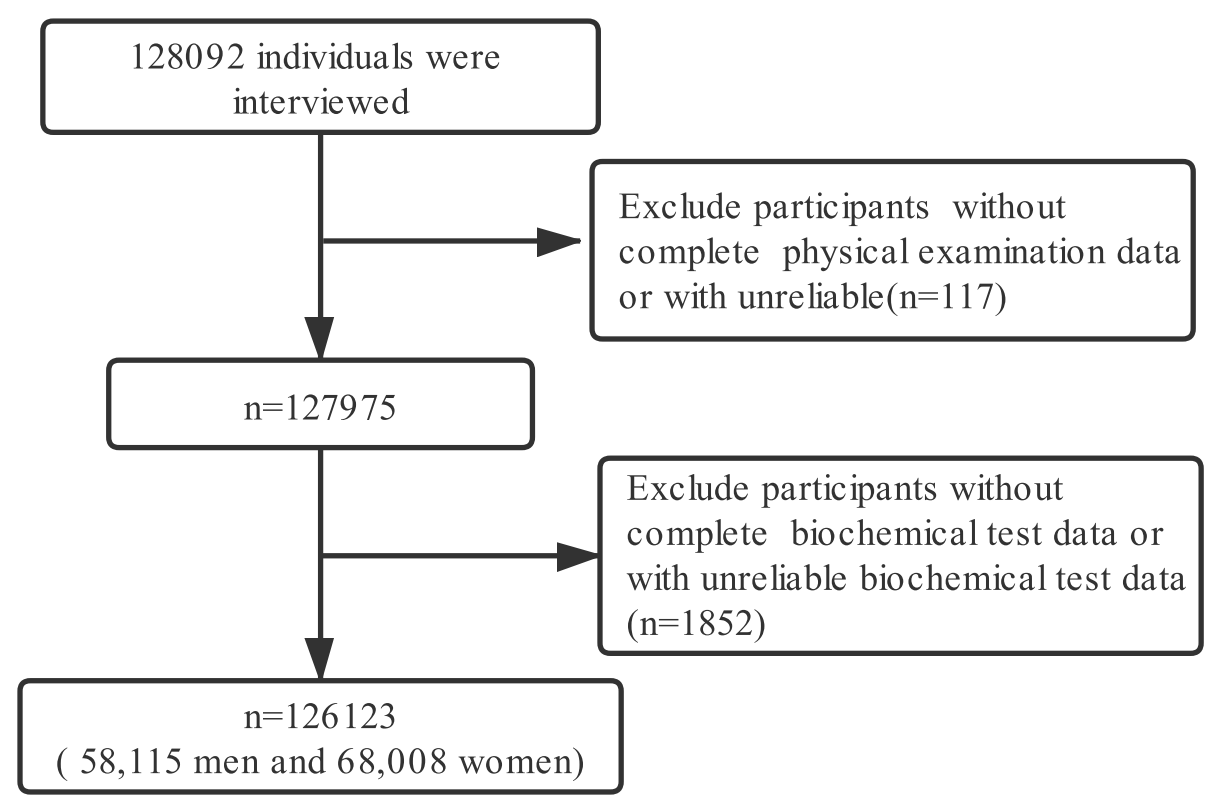

Fig. 1 Flow diagram of the selection of eligible participants

ORs and 95\% CIs for HBP were estimated for each group with adjustment of multiple confounders. One obesity parameter was introduced at a time in each model to avoid the collinear effect. Model 1 was unadjusted. Model 2 was adjusted for sex and age. Model 3 was adjusted for Model 2 and marital status, alcohol consumption, smoking, physical activity, place of residence, cancer, stroke, psychotic illness and blood glucose. A linear trend test was performed by modeling the median value of each exposure category as a continuous variable in the models. Fully adjusted restricted cubic spline analyses were used to characterize the doseresponse association and explore the potential linear or nolinear relationship of BMI, and WC with HBP. The knots were placed at the 5th, 25th, 50th, 75th and 95th percentiles. The test result for overall association was checked first. If the test for overall association was significant, the test result for nonlinearity and linearity were checked, and the $P$-value for non-linear association $<0.05$ indicated a significant result indicating the linear association. We also evaluated the additive interaction between BMI and WC for HBP with BMI and WC analyzed as continuous variable in two categories [(BMI: $\mathrm{BMI}<25$ and $\mathrm{BMI} \geq 25$. WC: $\mathrm{WC}<102$ for males, $\mathrm{WC}<$ 88 for females and $\mathrm{WC} \geq 102$ for males, $W C \geq 88$ for females) or (WHO proposed cut-off points [17])]. We applied three indicators to evaluate the additive interaction: relative excess risk due to interaction (RERI), attributable proportion due to interaction (AP) or synergy index $(\mathrm{S})$. RERI $>0$, AP $>0$, or $\mathrm{S}>1$ was regarded as a significant additive interaction.
Statistical analyses involved the use of SAS V .9.1 (SAS Institute) and $\mathrm{R} \times 64$ 4.0.0.All reported $P$ values were two-sided, with $P<0.05$ considered statistically significant.

\section{Results}

\section{Basic demographic characteristics}

A total of 126,123 participants were eligible for inclusion in this study. The mean (SD) age was 70.29 (6.94) years. The basic demographic characteristics of the study population according to BMI and WC quintiles are shown in Tables 1 and 2. The prevalence of HBP and stroke, levels of alcohol consumption, physical exercise and blood glucose showed a significant progressive increase from the quintile with the lowest BMI to the quintile with the highest BMI. This was also the case for the WC quintiles.

\section{OR and $95 \%$ confidence intervals (Cls) for HBP according to $\mathrm{BMI}$ and WC}

Table 3 presents the results from the logistic regression that estimated the association between the levels of BMI, WC and HBP. The multivariable adjusted OR $(95 \% \mathrm{CI})$ per $1 \mathrm{~kg} / \mathrm{m}^{2}$ increase in BMI was 1.084 (1.08 to 1.087 ). In all three models, the ORs for HBP increased significantly with increasing BMI quintiles ( $P$ for trend $<0.01$ ). In Model 3, the multivariate-adjusted OR (95\% CIs) for HBP with the highest BMI quintile group compared with the lowest quintile group was 2.300 (2.217 to 2.386 ). The multivariable adjusted OR $(95 \% \mathrm{CI})$ per $1 \mathrm{~cm}$ increase in WC was 1.025 (1.024 to 1.027). The highest quintile 
Table 1 Basic demographic characteristics of Subjects According to BMI Quintiles

\begin{tabular}{|c|c|c|c|c|c|c|}
\hline Characteristics & First Quintile & Second Quintile & Third Quintile & Fourth Quintile & Fifth Quintile & $P$ for trend \\
\hline Male & $\mathrm{BMI}<22.20$ & $22.20 \leq \mathrm{BMl}<24.02$ & $24.02 \leq \mathrm{BMI}<25.73$ & $25.73 \leq \mathrm{BMI}<27.78$ & $\mathrm{BMI} \geq 27.78$ & \\
\hline Female & $\mathrm{BMI}<22.43$ & $22.43 \leq \mathrm{BMl}<24.42$ & $24.42 \leq \mathrm{BMI}<26.27$ & $26.27 \leq \mathrm{BMI}<28.58$ & $\mathrm{BMI} \geq 28.58$ & \\
\hline No. & 25,164 & 25,236 & 25,166 & 25,268 & 25,289 & \\
\hline High blood pressure & & & & & & $<0.001$ \\
\hline no & $13,812(54.89)$ & $12,206(48.37)$ & $11,346(45.08)$ & $10,508(41.59)$ & $9205(36.4)$ & \\
\hline yes & $11,352(45.11)$ & $13,030(51.63)$ & $13,820(54.92)$ & $14,760(58.41)$ & $16,084(63.6)$ & \\
\hline Cancer & & & & & & 0.005 \\
\hline no & 25,137 (99.89) & 25,215 (99.92) & 25,146 (99.92) & 25,246 (99.91) & 25,282 (99.97) & \\
\hline yes & $27(0.11)$ & $21(0.08)$ & $20(0.08)$ & $22(0.09)$ & $7(0.03)$ & \\
\hline Stroke & & & & & & 0.003 \\
\hline no & 25,036 (99.49) & 25,099 (99.46) & $25,056(99.56)$ & $25,163(99.58)$ & 25,194 (99.62) & \\
\hline yes & $128(0.51)$ & $137(0.54)$ & $110(0.44)$ & $105(0.42)$ & $95(0.38)$ & \\
\hline Psychotic illness & & & & & & 0.009 \\
\hline no & 24,982 (99.28) & 25,107 (99.49) & $25,027(99.45)$ & $25,177(99.64)$ & $25,136(99.39)$ & \\
\hline yes & $182(0.72)$ & $129(0.51)$ & $139(0.55)$ & $91(0.36)$ & $153(0.61)$ & \\
\hline Age, years & $72.08 \pm 7.75$ & $70.54 \pm 7.17$ & $69.96 \pm 6.66$ & $69.59 \pm 6.49$ & $69.29 \pm 6.17$ & $<0.001$ \\
\hline sex, $\%$ & & & & & & 0.981 \\
\hline men & 11,619 (46.17) & $11,584(45.9)$ & $11,612(46.14)$ & $11,642(46.07)$ & $11,658(46.1)$ & \\
\hline women & $13,545(53.83)$ & $13,652(54.1)$ & $13,554(53.86)$ & $13,626(53.93)$ & $13,631(53.9)$ & \\
\hline Marital status, \% & & & & & & $<0.001$ \\
\hline unmarried & $558(2.22)$ & $432(1.71)$ & $341(1.36)$ & $285(1.13)$ & $246(0.97)$ & \\
\hline married & $19,847(78.87)$ & 20,968 (83.09) & $21,315(84.7)$ & $21,686(85.82)$ & 21,916 (86.66) & \\
\hline divorced & $135(0.54)$ & $91(0.36)$ & $124(0.49)$ & $92(0.36)$ & $83(0.33)$ & \\
\hline death of a spouse & $4624(18.38)$ & $3745(14.84)$ & $3386(13.45)$ & $3205(12.68)$ & $3044(12.04)$ & \\
\hline Smoking, \% & & & & & & $<0.001$ \\
\hline Never smokers & $20,950(83.25)$ & $21,506(85.22)$ & $21,557(85.66)$ & $21,879(86.59)$ & $22,079(87.31)$ & \\
\hline Former smokers & $537(2.13)$ & $591(2.34)$ & $611(2.43)$ & $623(2.47)$ & $678(2.68)$ & \\
\hline Current smokers & $3677(14.61)$ & $3139(12.44)$ & $2998(11.91)$ & $2766(10.95)$ & $2532(10.01)$ & \\
\hline Alcohol consumption, \% & & & & & & $<0.001$ \\
\hline Never & $23,681(94.11)$ & 23,651 (93.72) & 23,364 (92.84) & 23,379 (92.52) & 23,296 (92.12) & \\
\hline Once in a while & 906 (3.6) & $998(3.95)$ & $1113(4.42)$ & $1129(4.47)$ & $1215(4.8)$ & \\
\hline More than once a week & $243(0.97)$ & $277(1.1)$ & $305(1.21)$ & $350(1.39)$ & $352(1.39)$ & \\
\hline Every day & $334(1.33)$ & $310(1.23)$ & $384(1.53)$ & $410(1.62)$ & $426(1.68)$ & \\
\hline Physical exercise, \% & & & & & & $<0.001$ \\
\hline Never & $16,555(65.79)$ & $15,881(62.93)$ & $15,014(59.66)$ & 14,897 (58.96) & $15,290(60.46)$ & \\
\hline Once in a while & $863(3.43)$ & $912(3.61)$ & $943(3.75)$ & $998(3.95)$ & $966(3.82)$ & \\
\hline More than once a week & $1576(6.26)$ & $1809(7.17)$ & $1937(7.7)$ & $1914(7.57)$ & $1830(7.24)$ & \\
\hline Every day & $6170(24.52)$ & $6634(26.29)$ & $7272(28.9)$ & 7459 (29.52) & $7203(28.48)$ & \\
\hline Residence & & & & & & $<0.001$ \\
\hline Rural areas & 21,838 (86.78) & $20,703(82.04)$ & $20,322(80.75)$ & 20,314 (80.39) & 20,365 (80.53) & \\
\hline Urban areas & $3326(13.22)$ & $4533(17.96)$ & $4844(19.25)$ & $4954(19.61)$ & $4924(19.47)$ & \\
\hline Blood glucose, mmol/L & $5.44 \pm 1.8$ & $5.68 \pm 1.86$ & $5.82 \pm 1.91$ & $5.91 \pm 1.91$ & $6.04 \pm 1.95$ & $<0.001$ \\
\hline
\end{tabular}


Table 2 Basic demographic characteristics of Subjects According to WC Quintiles

\begin{tabular}{|c|c|c|c|c|c|c|}
\hline Characteristics & First Quintile & Second Quintile & Third Quintile & Fourth Quintile & Fifth Quintile & $P$ for trend \\
\hline Male & $W C<81$ & $81 \leq W C<86$ & $86 \leq W C<90$ & $90 \leq W C<96$ & $W C \geq 96$ & \\
\hline Female & $W C<79$ & $79 \leq W C<84$ & $84 \leq W C<89$ & $89 \leq W C<95$ & $W C \geq 95$ & \\
\hline No. & 23,098 & 23,498 & 24,971 & 26,736 & 27,820 & \\
\hline High blood pressure & & & & & & $<0.001$ \\
\hline no & $12,346(53.45)$ & $11,421(48.6)$ & $11,219(44.93)$ & $11,539(43.16)$ & $10,552(37.93)$ & \\
\hline yes & $10,752(46.55)$ & $12,077(51.4)$ & $13,752(55.07)$ & $15,197(56.84)$ & $17,268(62.07)$ & \\
\hline Age, years & $71.29 \pm 7.65$ & $70.48 \pm 7.15$ & $69.96 \pm 6.79$ & $69.86 \pm 6.57$ & $70.01 \pm 6.51$ & $<0.001$ \\
\hline sex, $\%$ & & & & & & 0.001 \\
\hline men & $10,850(46.97)$ & $10,887(46.33)$ & $10,190(40.81)$ & $13,076(48.91)$ & $13,112(47.13)$ & \\
\hline women & $12,248(53.03)$ & $12,611(53.67)$ & $14,781(59.19)$ & $13,660(51.09)$ & $14,708(52.87)$ & \\
\hline Cancer & & & & & & 0.076 \\
\hline no & 23,075 (99.9) & 23,479 (99.92) & 24,949 (99.91) & $26,720(99.94)$ & 27,803 (99.94) & \\
\hline yes & $23(0.1)$ & $19(0.08)$ & $22(0.09)$ & $16(0.06)$ & $17(0.06)$ & \\
\hline Stroke & & & & & & 0.008 \\
\hline no & $22,974(99.46)$ & 23,375 (99.48) & 24,869 (99.59) & $26,623(99.58)$ & 27,707 (99.59) & \\
\hline yes & $124(0.54)$ & $123(0.52)$ & $102(0.41)$ & $113(0.42)$ & $113(0.41)$ & \\
\hline Psychotic illness & & & & & & 0.091 \\
\hline no & $22,937(99.3)$ & $23,384(99.51)$ & $24,835(99.46)$ & $26,613(99.54)$ & $27,660(99.42)$ & \\
\hline yes & $161(0.7)$ & $114(0.49)$ & $136(0.54)$ & $123(0.46)$ & $160(0.58)$ & \\
\hline Marital status, \% & & & & & & $<0.001$ \\
\hline unmarried & $546(2.36)$ & $427(1.82)$ & $312(1.25)$ & $289(1.08)$ & $288(1.04)$ & \\
\hline married & $18,446(79.86)$ & $19,404(82.58)$ & $21,106(84.52)$ & $22,908(85.68)$ & 23,868 (85.79) & \\
\hline divorced & $120(0.52)$ & $99(0.42)$ & $106(0.42)$ & $103(0.39)$ & $97(0.35)$ & \\
\hline death of a spouse & $3986(17.26)$ & $3568(15.18)$ & $3447(13.8)$ & $3436(12.85)$ & $3567(12.82)$ & \\
\hline Smoking, \% & & & & & & $<0.001$ \\
\hline Never smokers & $19,441(84.17)$ & $19,920(84.77)$ & $21,755(87.12)$ & $22,749(85.09)$ & $24,106(86.65)$ & \\
\hline Former smokers & $469(2.03)$ & $534(2.27)$ & $555(2.22)$ & $748(2.8)$ & $734(2.64)$ & \\
\hline Current smokers & $3188(13.8)$ & $3044(12.95)$ & $2661(10.66)$ & $3239(12.11)$ & $2980(10.71)$ & \\
\hline Alcohol consumption, $\%$ & & & & & & $<0.001$ \\
\hline Never & $21,794(94.35)$ & $22,082(93.97)$ & $23,500(94.11)$ & $24,555(91.84)$ & $25,440(91.45)$ & \\
\hline Once in a while & 799 (3.46) & $913(3.89)$ & $927(3.71)$ & $1322(4.94)$ & $1400(5.03)$ & \\
\hline More than once a week & $208(0.9)$ & $217(0.92)$ & $233(0.93)$ & $406(1.52)$ & $463(1.66)$ & \\
\hline Every day & $297(1.29)$ & $286(1.22)$ & $311(1.25)$ & $453(1.69)$ & $517(1.86)$ & \\
\hline Physical exercise, \% & & & & & & $<0.001$ \\
\hline Never & $14,960(64.77)$ & $14,768(62.85)$ & $15,405(61.69)$ & $15,830(59.21)$ & $16,674(59.94)$ & \\
\hline Once in a while & $808(3.5)$ & $835(3.55)$ & $996(3.99)$ & $998(3.73)$ & $1045(3.76)$ & \\
\hline More than once a week & $1507(6.52)$ & $1790(7.62)$ & $1871(7.49)$ & $1962(7.34)$ & $1936(6.96)$ & \\
\hline Every day & $5823(25.21)$ & $6105(25.98)$ & $6699(26.83)$ & 7946 (29.72) & $8165(29.35)$ & \\
\hline Residence & & & & & & $<0.001$ \\
\hline Rural areas & $20,201(87.46)$ & $20,096(85.52)$ & 20,773 (83.19) & $21,110(78.96)$ & $21,362(76.79)$ & \\
\hline Urban areas & $2897(12.54)$ & $3402(14.48)$ & $4198(16.81)$ & $5626(21.04)$ & $6458(23.21)$ & \\
\hline Blood glucose, mmol/L & $5.44 \pm 1.71$ & $5.64 \pm 1.81$ & $5.76 \pm 1.88$ & $5.9 \pm 1.97$ & $6.08 \pm 2.01$ & $<0.001$ \\
\hline
\end{tabular}


Table 3 Association between BMI, WC and HBP

\begin{tabular}{llll}
\hline Characteristics & $\begin{array}{l}\text { Model 1 } \\
\text { OR(95\%Cl) }\end{array}$ & $\begin{array}{l}\text { Model 2 } \\
\text { OR(95\%Cl) }\end{array}$ & $\begin{array}{l}\text { Model 3 } \\
\text { OR(95\%Cl) }\end{array}$ \\
\hline $\begin{array}{ll}\text { BMl,per1 kg/m² change } \\
\text { BMl group }\end{array}$ & $1.077(1.074,1.08)$ & $1.085(1.081,1.088)$ & $1.084(1.080,1.087)$ \\
Q1 & $1.000($ ref $)$ & $1.000($ ref $)$ & $1.000($ ref $)$ \\
Q2 & $1.299(1.254,1.345)$ & $1.361(1.313,1.41)$ & $1.363(1.316,1.413)$ \\
Q3 & $1.482(1.431,1.535)$ & $1.581(1.525,1.638)$ & $1.580(1.524,1.637)$ \\
Q4 & $1.709(1.65,1.77)$ & $1.844(1.779,1.911)$ & $1.835(1.770,1.903)$ \\
Q5 & $2.126(2.051,2.203)$ & $2.317(2.235,2.403)$ & $2.300(2.217,2.386)$ \\
P for trend & $<0.001$ & $<0.001$ & $<0.001$ \\
WC,per1 cm change & $1.022(1.021,1.024)$ & $1.025(1.024,1.026)$ & $1.026(1.024,1.027)$ \\
WC group & & & $1.000(\mathrm{ref})$ \\
Q1 & $1.000(\mathrm{ref})$ & $1.000(\mathrm{ref})$ & $1.237(1.192,1.283)$ \\
Q2 & $1.214(1.171,1.259)$ & $1.239(1.195,1.286)$ & $1.445(1.394,1.499)$ \\
Q3 & $1.408(1.358,1.459)$ & $1.443(1.391,1.496)$ & $1.593(1.537,1.652)$ \\
Q4 & $1.512(1.46,1.567)$ & $1.577(1.522,1.635)$ & $1.977(1.906,2.050)$ \\
Q5 & $1.879(1.814,1.947)$ & $1.95(1.881,2.021)$ & $<0.001$ \\
P for trend & $<0.001$ & $<0.001$ & $<$ \\
\hline
\end{tabular}

$B M I$ body mass index, WC waist circumference. Model1: unadjusted. Model2: adjusted for sex and age. Model3 adjusted for Model2 and marital status, alcohol consumption, smoking, physical activity, place of residence,cancer, stroke, psychotic illness and blood glucose. Linear trend test was performed by modeling the median value of each exposure category as a continuous variable in the models

group had a greater HBP prevalence than the other quintile group, and the crude ORs (95\% CIs) for HBP compared with the lowest quintile group was 1.879 (1.814 to 1.947). After adjustment for sex, age, marital status, alcohol consumption, smoking, physical activity, place of residence and blood glucose, the ORs were enhanced, and the multivariate-adjusted ORs (95\% CIs) for HBP with the highest WC quintile group compared with the lowest quintile group was $1.977(1.906$ to 2.050 ).

\section{Dose response analysis}

Multivariable adjusted restricted cubic spline analyses showed the nonlinear relationships of BMI with HBP (all $P<0.001$; Fig. 2a). The risk of HBP increased with increasing BMI. As BMI increased, the ORs increased from $0.31(0.28$ to 0.35$)$ to $2.08(1.82$ to 2.39$)$ in the $15-$ $42 \mathrm{~kg} / \mathrm{m}^{2}$ range. As a result, the ORs were inversely associated with HBP when BMI was below $25 \mathrm{~kg} / \mathrm{m}^{2}$, but presented a significant risk effect above this value. Subgroup analyses on men-women did not show significant differences (Fig. 2b; c).

The results of the dose-response relationship analysis between WC and HBP are shown in Fig. 3a. A nonlinear association (all $P<0.001$ ) between WC and HBP was detected. As WC increased, the ORs increased from $0.32(0.27$ to 0.39$)$ to $2.57(2.24$ to 2.95$)$ in the $40-130 \mathrm{~cm}$ range. When stratified by sex, the ORs increased from $0.27(0.20$ to 0.37$)$ to 3.22 (2.62 to 3.97$)$ in the male population. With an increase in WC, when WC was over 88 $\mathrm{cm}$ and $86 \mathrm{~cm}$ for males and females, respectively, WC was more steeply positively associated with the risk of HBP (Fig. 3b; c).

\section{Additive interaction analysis}

Table 4 presents the results from additive interaction analysis. We observed a significant additive interaction between higher $\mathrm{BMI}$ and $\mathrm{WC}$ such that the prevalence of HBP increased (RERI $=1.28,95 \% \mathrm{CI}: 1.13-1.43$; $\mathrm{AP}=$ 0.43, 95\% CI: $0.41-0.45 ; \mathrm{S}=2.88,95 \% \mathrm{CI}: 2.79-2.97)$. If $\mathrm{BMI}<25.0 \mathrm{~kg} / \mathrm{m}^{2}$ and $\mathrm{WC}<88 \mathrm{~cm}$ for males and $\mathrm{WC}<$ $86 \mathrm{~cm}$ for females were used as the reference, $\mathrm{BMI} \geq 25$ alone and $\mathrm{WC} \geq 88$ for males or $\mathrm{WC} \geq 86$ for females alone were both associated with increased risks of HBP. The copresence of both factors greatly enhanced the adjusted ORs of higher BMI alone 1.476(1.418 to 1.536) and higher WC alone $1.230(1.186$ to 1.275$)$ to 1.729 (1.685 to 1.775$)$ for HBP, with significant additive interactions. When BMI and WC were classified by the proposed cut-off points [17] on the waist circumference continuum (BMI: $25 \mathrm{~kg} / \mathrm{m}^{2}$, WC: $88 \mathrm{~cm}$ for females and $102 \mathrm{~cm}$ for males), there was still significant additive interaction $(\mathrm{RERI}=1.68,95 \% \mathrm{CI}: 1.48-1.87$; $\mathrm{AP}=0.48$, 95\% CI: 0.46-0.50; $\mathrm{S}=3.00$, 95\% CI: $2.91-3.10$ ).

\section{Discussion}

In this study, the prevalence of HBP increased with rising $\mathrm{BMI}$ and $\mathrm{WC}$ in the older population of Xinzheng, China, in males and females and in the entire study 

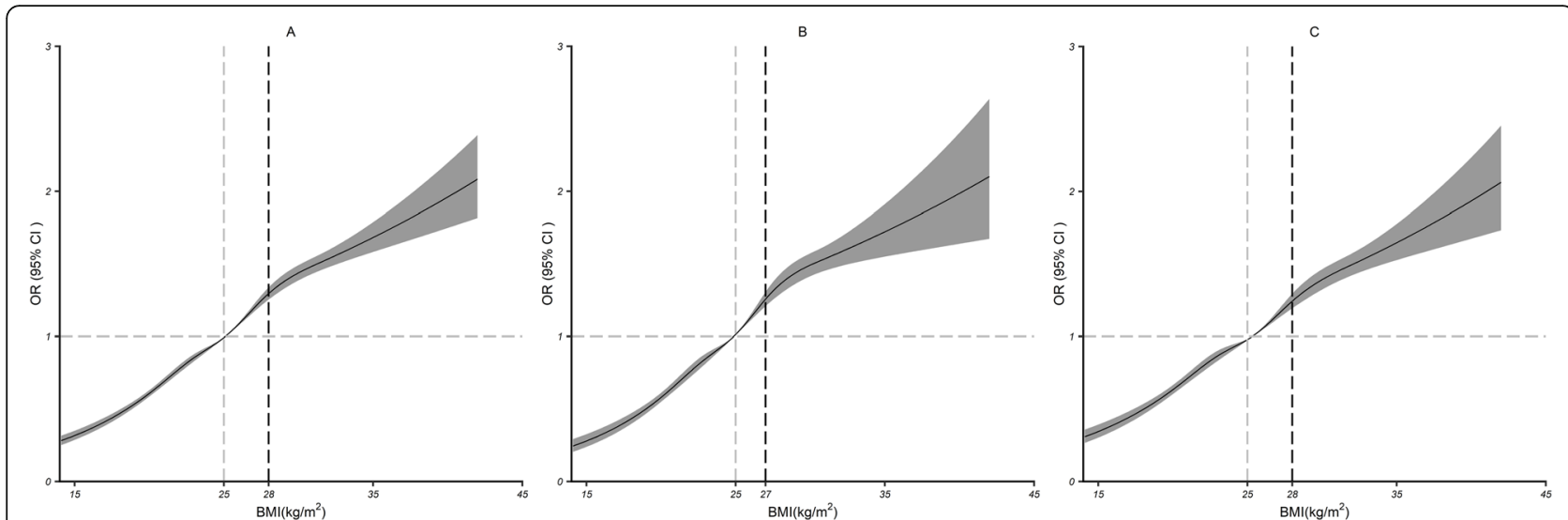

Fig. 2 Dose-response relationship between BMI and HBP. BMI and HBP outcomes in the total study population (a), male study population (b) and female study population (c). The associations were adjusted for age, marital status, alcohol consumption, smoking, physical activity, area, cancer, stroke, psychotic illness and blood glucose. The solid lines and gray areas represent the estimated ORs and their $95 \%$ Cls. The gray dashed lines represent the corresponding BMI when the OR is 1, and the black dashed lines represent the point where the slope suddenly decreases the most, corresponding to the BMI

population. These associations remained significant after adjustment for multiple factors and restricted cubic spline analysis showed clear dose-response relationships. At the same time, this study conducted an additive interaction analysis, which concluded a significant additive interaction between BMI and WC such that the prevalence of HBP increased. To some extent, this study provides a better understanding of the association of anthropometric indicators of obesity with HBP rather than focusing on individual indices, which would be more enlightening for HBP prevention.

Our study confirmed that there was a nonlinear doseresponse relationship between BMI and the risk of HBP, which was similar to previous studies $[18,19]$. However, a prospective study including 1412 subjects provided evidence that an increase in BMI is associated with a linearly increased adjusted risk of developing conditions with high HBP risk [20], possibly because of estimating the relationship using categorical measures of BMI, masking the shape of the dose-response relationship. Furthermore, in our large sample $(n=126,123)$, BMI below $25 \mathrm{~kg} / \mathrm{m}^{2}$ was regarded as a healthy weight for the older adults in terms of HBP prevalence. However, our proposed appropriate level for HBP were higher than those in some previous studies [21], which could be due to differences in the age range. The average age we sampled was much higher because BMI is greater in older populations, which might be a reason for the inconsistent findings, and when one of the studies stratified data by age ( $<50$ and $\geq 50$ years), the appropriate level for the

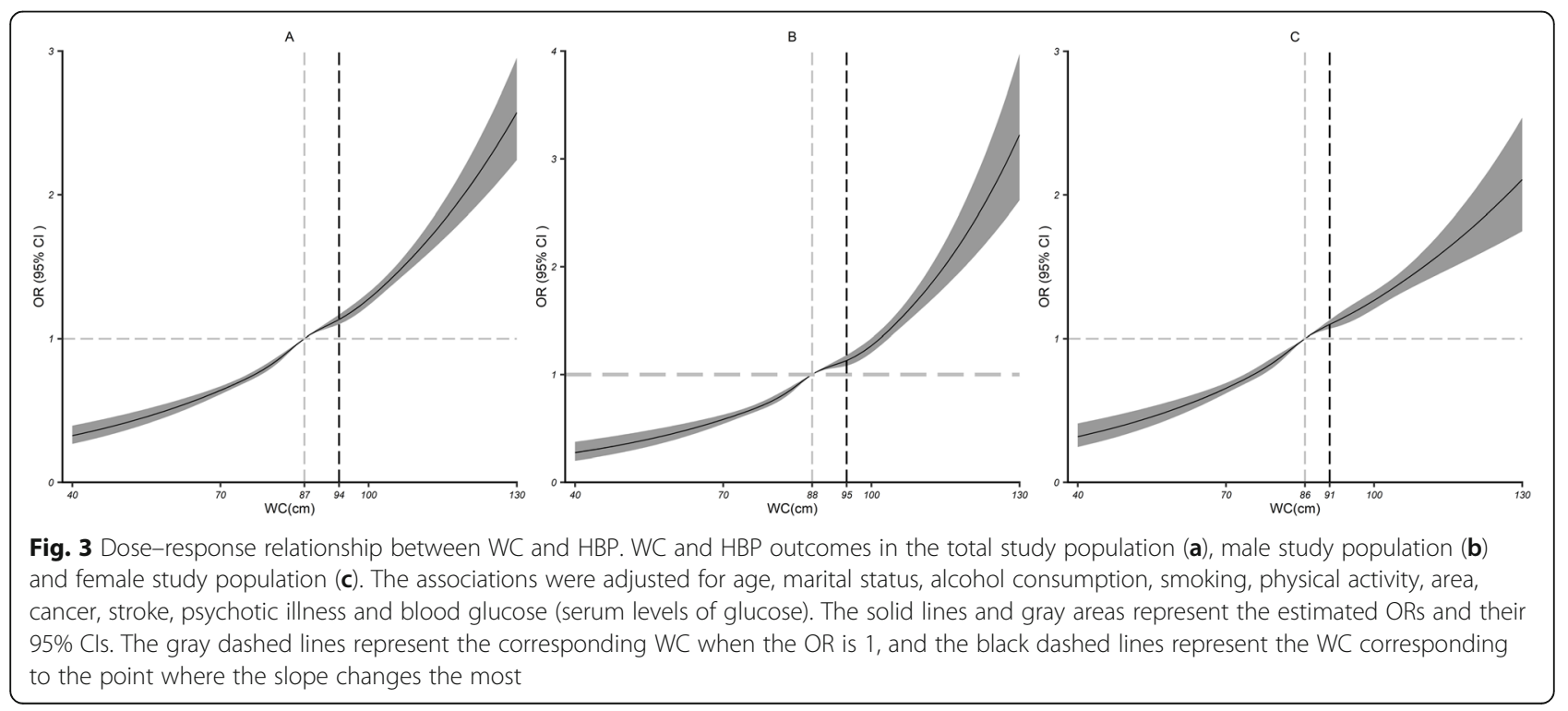


Table 4 Additive interaction analysis of BMI and WC for HBP

\begin{tabular}{|c|c|c|c|}
\hline \multirow[t]{2}{*}{ Characteristics } & Model 1 & Model 2 & Model 3 \\
\hline & $\mathrm{OR}(95 \% \mathrm{Cl})$ & $\mathrm{OR}(95 \% \mathrm{Cl})$ & $\mathrm{OR}(95 \% \mathrm{Cl})$ \\
\hline \multicolumn{4}{|l|}{ Additive interaction models1 } \\
\hline $\mathrm{BMI}<25$ and $\mathrm{WC}<88 / 102$ & 1.000 (ref) & 1.000 (ref) & 1.000 (ref) \\
\hline $\mathrm{BMI} \geq 25$ and $\mathrm{WC}<88 / 102$ & $1.459(1.42,1.5)$ & $1.546(1.503,1.589)$ & $1.517(1.476,1.56)$ \\
\hline $\mathrm{BMI}<25$ and $\mathrm{WC} \geq 88 / 102$ & $1.377(1.304,1.453)$ & $1.286(1.216,1.36)$ & $1.301(1.232,1.375)$ \\
\hline $\mathrm{BMI} \geq 25$ and $W C \geq 88 / 102$ & $1.749(1.699,1.799)$ & $1.757(1.705,1.811)$ & $1.771(1.719,1.823)$ \\
\hline \multicolumn{4}{|l|}{ Additive interaction models2 } \\
\hline $\mathrm{BMI}<25$ and $\mathrm{WC}<86 / 88$ & 1.000 (ref) & 1.000 (ref) & 1.000 (ref) \\
\hline $\mathrm{BMI} \geq 25$ and $\mathrm{WC}<86 / 88$ & $1.469(1.412,1.528)$ & $1.512(1.453,1.574)$ & $1.476(1.418,1.536)$ \\
\hline $\mathrm{BMI}<25$ and $\mathrm{WC} \geq 86 / 88$ & $1.215(1.172,1.26)$ & $1.214(1.171,1.259)$ & $1.230(1.186,1.275)$ \\
\hline $\mathrm{BMI} \geq 25$ and $\mathrm{WC} \geq 86 / 88$ & $1.662(1.62,1.705)$ & $1.727(1.683,1.772)$ & $1.729(1.685,1.775)$ \\
\hline
\end{tabular}

BMI body mass index, WC waist circumference. Model 1: unadjusted. Model 2: adjusted for sex and age. Model 3 adjusted for Model 2 and marital status, alcohol consumption, smoking, physical activity, place of residence, cancer, stroke, psychotic illness and blood glucose

older group was $<25 \mathrm{~kg} / \mathrm{m}^{2}$ for men and women [22]. Contrary to the three studies above, the NHANES study suggested $27 \mathrm{~kg} / \mathrm{m}^{2}$ as the value [23], but there may be innate or cultural differences between the U.S. and Asia, including dietary habits, macronutrient content, and physical activity habits. Given the marked variations in different world regions, countries and populations within countries, the use of unified range may underestimate or overestimate the health hazards [24]; thus, it is of great interest to determine the appropriate level for cardiovascular disease risks.

For WC, the relationship with HBP was reported by most studies $[25,26]$. Most studies have found a positive association between WC and HBP [27], whereas a null association was found in a prospective study from European populations [26]. The low participation rate and the relatively high study drop-out rate may bias the result. We highlighted the increased risk of HBP when WC was over $88 \mathrm{~cm}$ and $86 \mathrm{~cm}$ for males and females, respectively. Our proposed WC appropriate level is higher than those reported by M Gus et al. [28], and increasing WC over time could be the cause of the difference. The worldwide upward trend in obesity has been dramatic; from 2013 to 2018, the mean WC increased from $82 \mathrm{~cm}$ to $86.3 \mathrm{~cm}$ for men and from $79.1 \mathrm{~cm}$ to $83.4 \mathrm{~cm}$ for older women [29]. However, lower appropriate level were suggested by previous studies [30, 31], and ethnic and racial differences might explain the discrepancy between different studies.

To our knowledge, the present study is the first to report a synergistic effect of higher BMI and $\mathrm{WC}$ on the risk of HBP in the aged. In other words, the copresence of higher BMI and WC greatly increased the risk of HBP, more than the summation of the risks due to exposure to either of them. In a cohort of 17,803 pregnant Chinese women, the copresence of a higher BMI and WC interacts to further increase the risk of gestational diabetes mellitus [32]. In addition, RISKESDAS research showed that only when general obesity or overweight coexisted with central obesity was the prevalence of HBP significantly increased [13]. This finding supported the stable relation between excess body fat and blood pressure. It is generally believed that the increased body mass would raise blood volume and cardiac output and then lead to the inadequate vasodilatation while the increased activity of the sympathetic nervous system, abnormal rennin-angiotensinaldosterone relation and insulin resistance would arouse defects in the control of vascular resistance. These adverse vascular responses may dominate the development of obesity-associated HBP [33, 34]. Besides, natriuretic peptides and inflammatory adipokines have an active metabolic role on adipocytes, the deficit in natriuretic peptides and inflammatory adipokines may contribute to hypertension in obesity [35].

Several additional points warrant discussion. First, the findings of this cross-sectional study are not conclusive evidence of a causal relation of WC and BMI with HBP. And the measurement of blood pressure is not taking into account home or $24 \mathrm{~h}$ blood pressure levels. Thus, we must be cautious in interpreting the present results, and further studies are needed to clarify our findings. Second, as the study data come from the Chinese middle area among the older population, our proposed appropriate level for the indices are only valid for this population. Third, selection of the appropriate levels for BMI and WC for HBP was based on visual checking of the shapes of the OR curves. The true appropriate level of 
BMI and WC for HBP remained arbitrary and might deviate slightly from the selected values. However, to the best of our knowledge, our study is the first to explore the association between anthropometric Indicators of obesity and HBP among older people with a large sample size in central China, and it is of practical significance to improve relevant research. Second, this study is based on a comprehensive health check-up program, which not only contains data related to physical measurements and disease, but also includes information on demographic characteristics, physical activity, daily living habits and some blood biochemical tests, therefore, we can make full use of this information for a more comprehensive and reliable analysis.

\section{Conclusion}

Understanding the association between BMI, WC and risks of HBP is very important because various interpretations can lead to conflicting recommendations of ideal BMIs and WCs among the older adults. The results of this study revealed that being as lean as possible within the normal range may be a best suggestion in reducing the risks of HBP. However, further cohort studies and replication studies in Chinese and other populations are needed before the results can be used in clinical practice to detect high-risk older adults for early intervention.

\section{Abbreviations}

BMI: Body mass index; HBP: High blood pressure; WC: Waist Circumference; ANOVA: Analysis of variance; OR: Odds ratio; Cl: Confidence intervals; RCS: Restricted cubic spline; CHS centers: Community health service centers

\section{Supplementary Information}

The online version contains supplementary material available at https:/doi. org/10.1186/s12877-021-02154-5.

\section{Additional file 1}

\section{Acknowledgements}

The investigators thank the dedicated participants and all research staff of the study.

\section{Authors' contributions}

WLZ: Conceptualization, Methodology, Software, Formal analysis, Data Curation, Writing - Original Draft. KH: Validation, Data Curation, Investigation, Formal analysis. HZ \& XQH: Data Curation, Investigation. CYY \& XYZ: Funding acquisition. SHS: Funding acquisition, Project administration, Supervision, Revising it critically for important intellectual content, final approval of the version to be submitted. All authors read and approved the final manuscript.

\section{Funding}

This study was supported by National Key Research and Development Program "Research on prevention and control of major chronic noncommunicable diseases" of China (Grant NO: 2017YFC1307705). The funding body did not play any role in the design of the study and collection, analysis, and interpretation of data and in writing the manuscript.

\section{Availability of data and materials}

This data set is still being used for analysis. Please contact the corresponding author regarding access to the full dataset.

\section{Declarations}

Ethics approval and consent to participate

Written informed consent was obtained from each participant before data collection. The research ethics committee of Zheng Zhou University approved the current study methodology, protocol, and procedures. (Reference Number: ZZUIRB2019-019).

\section{Consent for publication}

Not applicable.

\section{Competing interests}

None declared.

\section{Author details}

1Department of Epidemiology and Health Statistics, College of Public Health, Zhengzhou University, Songhe Shi, 100 Kexue Avenue, Zhengzhou, Henan 450001, People's Republic of China. ${ }^{2}$ Department of Neurology, Chinese People's Liberation Army General Hospital, Beijing, People's Republic of China.

Received: 24 August 2020 Accepted: 15 March 2021

Published online: 19 April 2021

\section{References}

1. Collaborators GBDRF. Global, regional, and national comparative risk assessment of 84 behavioural, environmental and occupational, and metabolic risks or clusters of risks for 195 countries and territories, 19902017: a systematic analysis for the global burden of disease study 2017. Lancet. 2018:392(10159):1923-94.

2. Poulter NR, Prabhakaran D, Caulfield M. Hypertension. Lancet. 2015; 386(9995):801-12. https://doi.org/10.1016/S0140-6736(14)61468-9.

3. Mills KT, Bundy JD, Kelly TN, Reed JE, Kearney PM, Reynolds K, Chen J, He J. Global disparities of hypertension prevalence and control: a systematic analysis of population-based studies from 90 countries. Circulation. 2016; 134(6):441-50. https://doi.org/10.1161/CIRCULATIONAHA.115.018912.

4. Wang Z, Chen Z, Zhang L, Wang X, Hao G, Zhang Z, Shao L, Tian Y, Dong Y, Zheng C, Wang J, Zhu M, Weintraub WS, Gao R, On behalf of the China Hypertension Survey Investigators*. Status of hypertension in China: results from the China hypertension survey, 2012-2015. Circulation. 2018;137(22): 2344-56. https://doi.org/10.1161/CIRCULATIONAHA.117.032380.

5. Ortega FB, Lavie CJ, Blair SN. Obesity and cardiovascular disease. Circ Res. 2016;1 18(11):1752-70. https://doi.org/10.1161/CIRCRESAHA.115.306883.

6. González-Muniesa P, Mártinez-González MA, Hu FB, Després JP, Matsuzawa Y, Loos RJF, Moreno LA, Bray GA, Martinez JA. Obesity. Nat Rev Dis Primers. 2017:3(1):17034. https://doi.org/10.1038/nrdp.2017.34

7. Lu J, Bi Y, Ning G. Curbing the obesity epidemic in China. Lancet Diabetes Endocrinol. 2016:4(6):470-1. https://doi.org/10.1016/\$2213-8587(16)30007-9.

8. Flegal KM, loannidis JPA, Doehner W. Flawed methods and inappropriate conclusions for health policy on overweight and obesity: the global BMI mortality collaboration meta-analysis. J Cachexia Sarcopenia Muscle. 2019; 10(1):9-13. https://doi.org/10.1002/jcsm.12378.

9. Geserick M, Vogel M, Gausche R, Lipek T, Spielau U, Keller E, Pfäffle R, Kiess W, Körner A. Acceleration of BMI in early childhood and risk of sustained obesity. N Engl J Med. 2018;379(14):1303-12. https://doi.org/10.1056/ NEJMoa1803527.

10. Adab P, Pallan M, Whincup PH. Is BMl the best measure of obesity? BM 2018;360:k1274.

11. Seo DC, Choe S, Torabi MR. Is waist circumference $\geq 102 / 88 \mathrm{~cm}$ better than body mass index $\geq 30$ to predict hypertension and diabetes development regardless of gender, age group, and race/ethnicity? Meta-analysis. Prev Med. 2017:97:100-8. https://doi.org/10.1016/j.ypmed.2017.01.012.

12. Chen $Y$, Liang $X$, Zheng S, Wang Y, Lu W. Association of Body Fat Mass and Fat Distribution With the Incidence of Hypertension in a Population-Based Chinese Cohort: A 22-Year Follow-Up. J Am Heart Assoc. 2018;7(6):e007153. https://doi.org/10.1161/JAHA.117.007153.

13. Nurdiantami Y, Watanabe K, Tanaka E, Pradono J, Anme T. Association of general and central obesity with hypertension. Clin Nutr. 2018;37(4):125963. https://doi.org/10.1016/j.clnu.2017.05.012.

14. Xu RY, Zhou YQ, Zhang XM, Wan YP, Gao X. Body mass index, waist circumference, body fat mass, and risk of developing hypertension in 
normal-weight children and adolescents. Nutr Metab Cardiovasc Dis. 2018 28(10):1061-6. https://doi.org/10.1016/j.numecd.2018.05.015.

15. Chobanian AV, Bakris GL, Black HR, Cushman WC, Green LA, Izzo JL Jr, Jones DW, Materson BJ, Oparil S, Wright JT Jr, et al. Seventh report of the joint National Committee on prevention, detection, evaluation, and treatment of high blood pressure. Hypertension. 2003:42(6):1206-52. https://doi.org/10.11 61/01.HYP.0000107251.49515.c2.

16. Tomar SL, Asma S. Smoking-attributable periodontitis in the United States: findings from NHANES III. National Health and nutrition examination survey. J Periodontol. 2000;71(5):743-51. https://doi.org/10.1902/jop.2000.71.5.743.

17. Kopelman PG. Obesity as a medical problem. Nature. 2000;404(6778):635-43. https://doi.org/10.1038/35007508.

18. Qu Y, Niu H, Li L, Li M, Yan S, Li M, Jiang S, Ma X, Li B, Wu H. Analysis of dose-response relationship between BMl and hypertension in northeastern China using restricted cubic spline functions. Sci Rep. 2019;9(1):18208. https://doi.org/10.1038/s41598-019-54827-2.

19. Jayedi A, Rashidy-Pour A, Khorshidi M, Shab-Bidar S. Body mass index, abdominal adiposity, weight gain and risk of developing hypertension: a systematic review and dose-response meta-analysis of more than 2.3 million participants. Obes Rev. 2018;19(5):654-67. https://doi.org/10.1111/obr.12656.

20. Bombelli M, Facchetti R, Sega R, Carugo S, Fodri D, Brambilla G, Giannattasio C, Grassi G, Mancia G. Impact of body mass index and waist circumference on the long-term risk of diabetes mellitus, hypertension, and cardiac organ damage. Hypertension. 2011; 58(6):1029-35. https//doi.org/10.1161/HYPERTENSIONAHA.111.175125.

21. Hossain FB, Adhikary G, Chowdhury AB, Shawon MSR. Association between body mass index (BMI) and hypertension in south Asian population: evidence from nationally-representative surveys. Clin Hypertens. 2019;25(1): 28. https://doi.org/10.1186/s40885-019-0134-8.

22. Feng RN, Zhao C, Wang C, Niu YC, Li K, Guo FC, Li ST, Sun CH, Li Y. $\mathrm{BMl}$ is strongly associated with hypertension, and waist circumference is strongly associated with type 2 diabetes and dyslipidemia, in northern Chinese adults. J Epidemiol. 2012;22(4):317-23. https://doi. org/10.2188/jea.JE20110120.

23. Kuwabara M, Kuwabara R, Niwa K, Hisatome I, Smits G, Roncal-Jimenez CA, MacLean PS, Yracheta JM, Ohno M, Lanaspa MA et al. Different Risk for Hypertension, Diabetes, Dyslipidemia, and Hyperuricemia According to Level of Body Mass Index in Japanese and American Subjects. Nutrients. 2018;10(8):1011. https://doi.org/10.3390/nu10081011.

24. Jiang M, Zou Y, Xin Q, Cai Y, Wang Y, Qin X, Ma D. Dose-response relationship between body mass index and risks of all-cause mortality and disability among the elderly: a systematic review and meta-analysis. Clin Nutr. 2019;38(4):1511-23. https://doi.org/10.1016/j.Inu.2018.07.021.

25. Luz RH, Barbosa AR, d'Orsi E. Waist circumference, body mass index and waist-height ratio: are two indices better than one for identifying hypertension risk in older adults? Prev Med. 2016;93:76-81. https://doi.org/1 0.1016/j.ypmed.2016.09.024.

26. Seven $E$, Thuesen $B H$, Linneberg $A$, Jeppesen JL. Abdominal adiposity distribution quantified by ultrasound imaging and incident hypertension in a general population. Hypertension. 2016;68(5):1115-22. https://doi.org/1 0.1161/HYPERTENSIONAHA. 116.07306

27. Garrison RJ, Kannel WB, Stokes J 3rd, Castelli WP. Incidence and precursors of hypertension in young adults: the Framingham offspring study. Prev Med. 1987;16(2):235-51. https://doi.org/10.1016/0091-7435(87)90087-9.

28. Gus M, Cichelero FT, Moreira CM, Escobar GF, Moreira LB, Wiehe M, Fuchs SC, Fuchs FD. Waist circumference cut-off values to predict the incidence of hypertension: an estimation from a Brazilian population-based cohort. Nutr Metab Cardiovasc Dis. 2009;19(1):15-9. https://doi.org/10.1016/..numecd.2 008.03.007.

29. Bragg F, Tang K, Guo Y, Iona A, Du H, Holmes MV, Bian Z, Kartsonaki C, Chen $Y$, Yang $L$, et al. Associations of general and central adiposity with incident diabetes in Chinese men and women. Diabetes Care. 2018;41(3): 494-502. https://doi.org/10.2337/dc17-1852.

30. Khader Y, Batieha A, Jaddou H, El-Khateeb M, Ajlouni K. The performance of anthropometric measures to predict diabetes mellitus and hypertension among adults in Jordan. BMC Public Health. 2019;19(1):1416. https://doi. org/10.1186/s12889-019-7801-2

31. Ramezankhani A, Ehteshami-Afshar S, Hasheminia M, Hajebrahimi MA, Azizi F, Hadaegh F. Optimum cutoff values of anthropometric indices of obesity for predicting hypertension: more than one decades of follow-up in an Iranian population. J Hum Hypertens. 2018;32(12):838-48. https://doi.org/1 0.1038/s41371-018-0093-7.
32. Han Q, Shao P, Leng J, Zhang C, Li W, Liu G, Zhang Y, Li Y, Li Z, Ren Y, Chan $J C N$, Yang $X$. Interactions between general and central obesity in predicting gestational diabetes mellitus in Chinese pregnant women: a prospective population-based study in Tianiin, China. J Diabetes. 2018;10(1):59-67. https://doi.org/10.1111/1753-0407.12558.

33. Aroor AR, Jia G, Sowers JR. Cellular mechanisms underlying obesity-induced arterial stiffness. Am J Physiol Regul Integr Comp Physiol. 2018;314(3):R38798. https://doi.org/10.1152/ajpregu.00235.2016.

34. Asghar A, Sheikh N. Role of immune cells in obesity induced low grade inflammation and insulin resistance. Cell Immunol. 2017;315:18-26. https:// doi.org/10.1016/j.cellimm.2017.03.001.

35. Sarzani R, Bordicchia M, Spannella F, Dessì-Fulgheri P, Fedecostante M. Hypertensive heart disease and obesity: a complex interaction between hemodynamic and not hemodynamic factors. High Blood Press Cardiovasc Prev. 2014;21(2):81-7. https://doi.org/10.1007/s40292-014-0054-3.

\section{Publisher's Note}

Springer Nature remains neutral with regard to jurisdictional claims in published maps and institutional affiliations.

\section{Ready to submit your research? Choose BMC and benefit from:}

- fast, convenient online submission

- thorough peer review by experienced researchers in your field

- rapid publication on acceptance

- support for research data, including large and complex data types

- gold Open Access which fosters wider collaboration and increased citations

- maximum visibility for your research: over $100 \mathrm{M}$ website views per year

At BMC, research is always in progress.

Learn more biomedcentral.com/submissions 